\title{
Pequena infância, educação e gênero: subsídios para um estado da arte*
}

\author{
Ana Lúcia Goulart de Faria**
}

\begin{abstract}
Resumo
Com o objetivo de iniciar a descrição de um estado da arte este texto reúne pesquisas até então esparsas da área da educação infantil (primeira etapa da educação básica) que analisam as relações de poder entre meninas e meninos de 0 a 6 anos que freqüentam, por longas horas do dia, creches e pré-escolas; entre elas $e$ eles $e$ as profissionais predominantemente do sexo feminino, por opção de suas mães (e às vezes também de seus pais) $e$ investigam também as relações de poder entre essas mulheres adultas. O texto mostra que também por trazer a criançada, principalmente as pequenas, para assumir seu papel na construção da realidade, a luta feminista é grande responsável pelas modificações sociais da gestão do tempo cotidiano.
\end{abstract}

Palavras-chave: Pequena Infância, Movimento Feminista,

Relações de Gênero, Educação Infantil,

Creche, Pré-Escola

\footnotetext{
" Recebido para publicação em março de 2006, aprovado em maio de 2006.

** Professora da Faculdade de Educação da Unicamp. cripeq@unicamp.br
} 
Pequena infância, educação e gênero

\title{
Early Childhood, Education and Gender:
}

Elements Towards a State-of-the-Art.

\begin{abstract}
With the aim of starting up a description of the present state-ofthe-art, this work brings together research thus far sparsely developed in the field of early childhood education (the first stage in basic education in Brasil), which analyzes power relationships between zero-to-six year old girls and boys, who attend day-care centers and pre-schools for many hours a day; between them and the predominantly female professionals in those places, as a results of an option made by their mothers (and sometimes also their fathers) and also investigate the power relationships between these adult women. The text also shows that, by bringing children, particularly young children, to assume their role in constructing reality, the feminists struggle plays an important role in producing social changes to the management of everyday time.
\end{abstract}

Key Words: Young Children, Feminist Movement, Gender

Relationship, Early Childhood Education,

Day-Care center, Pre-School. 
Ana Lúcia Goulart de Faria

Josefina, professora de uma creche, estava entretida com um grupinho de crianças (a maioria delas com três anos de idade) que se travestiam das mais diferentes personagens. Algumas passavam baton,outras colocavam chapéu, cintos, capas, outras salto alto $e$ algumas meninas pediram para Josefina pintar-lhes as unhas da mão. De repente vem o Toninho e pede que ela pinte também as suas. Era a primeira vez que assim acontecia. Nossa professora ficou confusa, preocupada com $o$ que as mães $e$ os pais pudessem achar disto e para ganhar tempo enquanto pensava como proceder perguntou para ele

- Você já pintou as unhas antes? Seu pai pinta as unhas?

E ele respondeu prontamente

- Ah, eu nunca pintei antes. Meu pai não pinta também.

Bela resposta pensou, e eu, o que faço? Pergunto mais alguma coisa, quem sabe ele muda de idéia

- De que cor você quer pintar?

E decidido Toninho responde

- VER-ME-LHO.

E agora? Lá se foi meu emprego... Bom, mais uma pergunta, e quem sabe tudo se resolve

- Mas porque vermelho?

E Toninho responde todo feliz

- É a cor do Schumacher! ${ }^{1}$

Pretendo nesta poucas páginas introduzir a questão complexa das relações de gênero e a primeira, primeiríssima infância. Pode-se falar em relações de gênero neste mundo infantil? ${ }^{2}$ Esta pergunta acompanha as pesquisadoras feministas da pequena infância que hoje vem sendo sistematizada numa

1 Contada por uma ex-aluna, a quem agradeço a autorização para reproduzi-la aqui, trata-se de uma história verdadeira adaptada para preservar as privacidades.

2 Interessante perceber que em algumas línguas tais como português (criança), francês (enfant) e inglês (child), a palavra criança é sobrecomum e não é do gênero masculino e feminino como, por exemplo, em italiano (bambino, bambina) e espanhol (niños, niñas). 
Pequena infância, educação e gênero

Sociologia da infância que se apóia em categorias como "tempo" e "culturas infantis" e também numa Pedagogia da educação infantil que se funda no espaço e no tempo que constrói a condição infantil na esfera pública. Assim, neste texto, homenagearei as mulheres pesquisadoras que desde os meados dos anos de 1970, no interior dos movimentos feministas, vêm identificando o papel da infância na construção da realidade social, analisando o nexo entre autonomia e dependência nas atuais modificações sociais da gestão do tempo cotidiano, enfim, de fato dando a luz conhecendo a criança pequena na esfera pública, em suas múltiplas manifestações, onde

no interior desse crescimento esquizofrênico da importância do valor da infância permanece a rejeição de sua alteridade -, isto é, da sua diversidade-diferença, do seu anarquismo $e$ da sua libido perversa-polimorfa, do escândalo que provoca pela sua ligação muito forte com a natureza $e$ a sua distância-estranheza em relação à cultura. ${ }^{3}$

Não é por acaso que a década da criança, anos 80 , é posterior à década da mulher.

Se lembrarmos que até bem pouco tempo considerava-se que as pessoas só começavam a ser a partir dos 7 anos de idade, na escola obrigatória, para ainda mais tarde, de fato serem capazes de fazer os raciocínios "superiores" quando já significava estar saindo da infância! Com o paradigma do "penso, logo existo" tinha seu significado. Foi com as pesquisas recentes destes últimos 30 anos que passou-se a observar o que as crianças pequenas fazem quando estão entre elas num ambiente coletivo organizado não por parentes, mas por profissionais adultos e/ou adultos com intencionalidade educativa. Ainda com forte viés na psicologia essa pesquisa vai se tornando multidisciplinar para

3 Kulhmann JR., Moysés. Infância e educação infantil - uma abordagem histórica. Porto Alegre, Mediação, 1998, p.21. 
conhecer o "cidadão de pouca idade" (como diz Benjamin) para além da patologização, do higienismo, da incompletude, do apenas um vir-a-ser. ${ }^{4}$

A sequência de imagens que segue, mostra a menina Laura, de 8 meses, fotografada em 1989 numa creche pública italiana por uma colega da sua professora. ${ }^{5}$ Vemos assim uma criança pequenininha mostrando num curto espaço de tempo (e não apenas ao longo da vida, nas ditas etapas etárias de desenvolvimento) sua forma sofisticada de pensar (bastante parecida com a dos cientistas como diria Piaget).

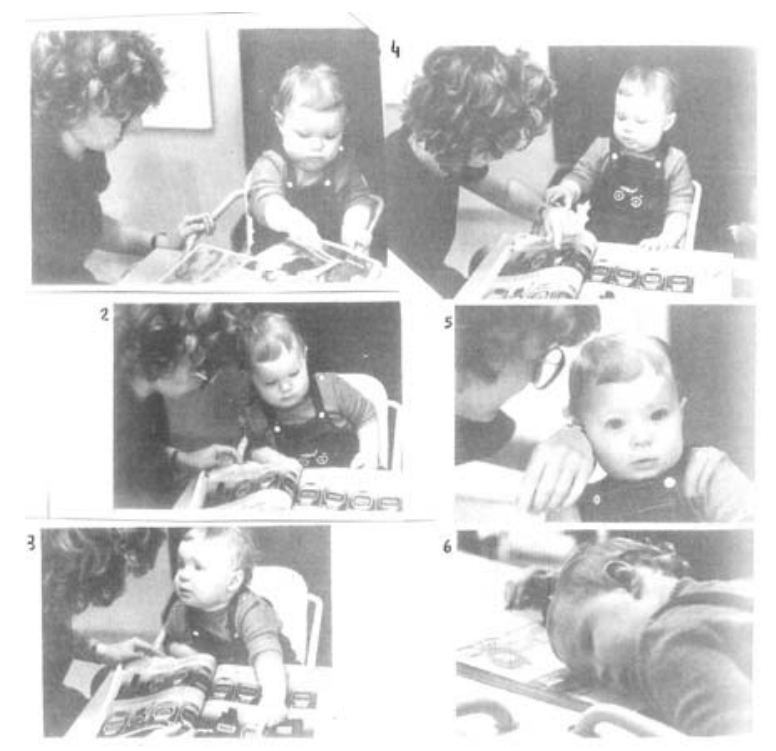

\footnotetext{
${ }^{4}$ Antes ainda, os países do leste europeu já vinham fazendo estas pesquisas, por exemplo, a experiência da escola não-autoritária riechiana em Berlim, o Instituto Pickler em Lockzy na Hungria com a palavra de ordem das crianças pequenininhas "me dêem tempo".

5 Mesmo com o hábito de documentar a prática pedagógica, a colega disse: "tive sorte, pois vi o que estava acontecendo e estava com filme na máquina".
} 
Pequena infância, educação e gênero

Justamente é o ingresso em massa das mulheres no mercado de trabalho e o movimento feminista que vai exigir creches para dividir com a sociedade a educação de seus filhos e filhas, articulado aos movimentos sindicais e das esquerdas. Num primeiro momento nos anos 70 a luta é por uma creche para nós, as mulheres: "tenho direito de trabalhar, estudar, namorar e ser mãe. Sem creche não poderei curtir todos eles". O prazer do convívio das crianças nas primeiras creches (ditas) selvagens, italianas e francesas, por exemplo, levou pesquisadoras feministas a observarem como são as crianças quando estão fora da família, o que levará, nos anos 80 , o próprio movimento feminista a levantar a bandeira também de creches para as crianças pequenas e não só para suas mães trabalhadoras. A primeira orientação para a educação das crianças em creches realizada no Brasil foi feita pelo Conselho Nacional dos Direitos da Mulher (CNDM) e pelo Conselho Estadual da Condição Feminina (CECF) denominada "Creche-urgente". Hoje conquistamos, já no papel, tanto o direito trabalhista dos "trabalhadores e trabalhadoras, rurais e urbanos" para que seus filhos e filhas sejam educados/as em creches e pré-escolas, como o direito de todas as crianças de 0 a 6 anos de serem, por opção de suas famílias, educadas fora da esfera privada, por profissionais formadas para isso (e não para antecipar a escola obrigatória). ${ }^{6}$ Temos hoje no mundo ocidental a creche como um patrimônio do feminismo, da esquerda e do sindicalismo dos anos 70. Assim, com uma história completamente diferente da história da escola, a creche é um direito à educação também diferente. Ela é constituída por três atores: pais e mães, professoras e crianças. Articula o direito à educação das crianças

${ }^{6}$ Cabe esclarecer que são direitos conquistados na Constituição de 1988, mas que não são auto-aplicáveis $e$, ainda hoje, não está definida a verba própria que garantirá sua aplicação. Em 1996 a Nova Lei e Diretrizes e Base da Educação Nacional define pela primeira vez na história do Brasil a Educação Infantil em creches e pré-escolas para as crianças de 0 a 6 anos de idade como a primeira etapa da Educação Básica (a segunda é o ensino fundamental e depois é o ensino médio). 
pequenas com o direito trabalhista dos seus pais e mães. Neste espaço da sociedade vivemos as mais distintas relações de poder: gênero, classe, idade e, lógico, étnicas. Ainda estão para serem melhor e mais estudadas e investigadas as relações no contexto da creche onde confrontam-se adultos - entre eles, professor/a, diretora, cozinheira, guarda, pai, mãe ${ }^{7}$, secretário/a de educação, prefeito/a, vereador/a, etc. -; confrontam-se crianças, entre elas: menino, menina, mais velha, mais nova, negra, branca, judia, com necessidades especiais, pobre, rica, de classe média, católica, umbandista, atéia, "café com leite", "quatro olhos", etc); e confrontam-se adultos e crianças - a professora e as meninas, a professora e os meninos, o professor (percentual bastante baixo, mas existente e com tendência a lento crescimento) e os meninos, o professor e as meninas, o professor e a mãe da menina...

Os resultados das pesquisas na área educacional (embora não escolar), em espaços coletivos de educação e cuidado, têm mostrado que as crianças pequenas de 0 a 6 anos são capazes de múltiplas relações, são portadoras de história, são produtoras de culturas infantis, são sujeitos de direitos. Ela é criança além de ser filha referendada no adulto Assim, a infância, que não se esgota aos 6 anos de idade ${ }^{8}$, é vista como uma fase da vida tão provisória (e concomitante) como as outras fases. Destaca-se de forma híbrida as metodologias não convencionais para investigar a pequena infância principalmente i piccolissimi como a Laura, que não falam, não andam, não escrevem e não lêem as letras (numa sociedade grafocêntrica! adultocêntrica!): partem de princípio marxista "o homem faz a história em condições dadas" (seja, homem, mulher, adulto, jovem, velho, criança...), no entanto, a problematização com os novos atores sociais é colocada pela pósmodernidade. A decana Egle Becchi da Universidade de Pavia (Itália) chama a atenção do caráter supra-interpretativo da

\footnotetext{
7 No âmbito de nossas pesquisas temos falado em parentalidade.

${ }^{8} \mathrm{Na}$ lei brasileira, o ECA - Estatuto da Criança e do Adolescente - estabelece a infância de 0 até os 12 anos de idade.
} 
Pequena infância, educação e gênero

pesquisa com criança. $^{9}$ Ela mostra o caráter interpretativo, por exemplo, na pesquisa sobre mulheres: as outras mulheres que lerem os resultados podem discordar, debater enfim, com as subjetividades aí explícitas (e implícitas também no tipo de infância que viveu o/a pesquisador/a) dependendo, inclusive, se a pesquisa foi realizada por homem ou por mulher. No caso da pequena infância ela diz que isso não será possível: as crianças pequenas não poderão ter este tipo de participação, não são elas que interpretam. Assim, o rigor e a ética do/a pesquisador/as será redobrado. Já nos disse Mario de Andrade "menino, tu me recordas a minha presença em mim. E eu sofro".

O bom selvagem, a construção do indivíduo, o iluminismo, o romantismo, a criança na fábrica, o realismo socialista, a dupla alienação da infância ${ }^{10}$, o expressionismo, temos, se estivéssemos falando em correntes artísticas: "as crianças são pop". ${ }^{11}$ Uma outra Pedagogia, portanto, se impõe: uma pedagogia da escuta, uma pedagogia das relações, uma pedagogia da diferença, o que chamei no meu doutorado de pedagogia macunaímica, onde além das ciências que a Pedagogia busca suas bases epistemológicas, também a arte é seu fundamento, garantindo assim a ausência de modelos rígidos preparatórios para a fase seguinte e, além de um cognitivismo característico das pedagogias, também a construção de todas as dimensões humanas e o convívio com a diferença, "sem nenhum caráter".

Sobre a pesquisa da pequena infância e as relações de gênero na educação infantil, tanto em creches como em préescolas, estamos numa trajetória promissora. Pesquisas sobre

9 BECCHI, Egle. Molte infanzia,poche storie. Richerche Pedagogiche, n's 68-9, Parma, 1983, pp.1-15.

${ }^{10}$ Trata-se da concomitância nas sociedades contemporâneas que encurtam a infância, de infâncias privatizadas e de infâncias exploradas.Impedidas, muitas vezes do direito de brincar com seus pares (embora, as pesquisa tem demonstrado que transgridem).

${ }^{11}$ Ouvi esta expressão de uma professora de creche italiana no Festival de teatro para bebês em março de 2006 em Bologna. 
brincadeiras e jogos entre meninos e meninas ${ }^{12}$, ou sobre desenhos como documentos de meninos e meninas ${ }^{13}$, por exemplo, tem mostrado outras formas de construção cultural do feminino e do masculino. A presença masculina nas creches ${ }^{14}$ tem questionado o "cuidado" como manifestação exclusivamente feminina, um outro exemplo que aponta para a construção de uma sociedade mais justa, menos sexista.

Eloísa Rocha ${ }^{15}$ elaborou um primeiro estado da arte das pesquisas (apresentadas em congressos nos anos 90) sobre a educação das crianças de 0 a 6 anos em creches e pré-escolas surpresa com a ausência das análises sobre relações de gênero (entre outras) e o reduzido número de pesquisas sobre as crianças pequenininhas. Nos últimos anos, essa situação não foi resolvida, mas com certeza foi amenizada num cenário complicado onde apenas 3\% das pesquisas apresentadas nos congressos da ANPED analisaram as relações de gênero. ${ }^{16}$ Finalizo insistindo que a superação da desigualdade com certeza passa pela educação desde a primeiríssima infância em espaços coletivos na esfera pública convivendo com as diferenças.

\footnotetext{
${ }^{12}$ FINCO, Daniela. Faca sem ponta, galinha sem pé, homem com homem mulher com mulher - relações de gênero nas brincadeira numa pré-escola de Campinas. Dissertação de mestrado, FE-Unicamp, 2004.

${ }^{13}$ GoBBi, Marcia. Lápis vermelho é de mulherzinha- relações de gênero, desenho infantil e pré-escola. Dissertação de mestrado, FE-Unicamp, 1997.

${ }^{14}$ SAYÃO, Deborah. Homens docentes e o cuidado em creches. Tese de doutorado, FE-UFSC, 2005

${ }^{15}$ Rocha, Eloisa. A pesquisa em educação infantil no Brasil - trajetória recente e perspectivas de consolidação de uma Pedagogia da educação infantil. Florianópolis, Editora da UFSC, 1999.

${ }^{16}$ Rosemberg, Fulvia.Caminhos cruzados: educação e gênero na produção acadêmica. Educação e Pesquisa, vol.27, nº 1, FE-USP, 2001, pp.47-68.
} 